\title{
Changes of Occupational Noise-Induced Hearing Loss due to Working in the Steel Industry and Associated Effective Factors: Application of Bayesian Multivariate Multilevel Modeling using Skew Distribution
}

\author{
Abolfazl Nikpour ${ }^{1}$ and Mohammad Gholami Fesharaki2,, \\ ${ }^{1} \mathrm{PhD}$ Student of Biostatistics, Department of Biostatistics, Faculty of Medical Sciences, Tarbiat Modares University, Tehran, Iran \\ 2 Assistant Professor of Biostatistics, Department of Biostatistics, Faculty of Medical Sciences, Tarbiat Modares University, Tehran, Iran \\ * Corresponding author: Mohammad Gholami Fesharaki, Department of Biostatistics, Faculty of Medical Sciences, Tarbiat Modares \\ University, Ale-Ahmad Highway, Tehran, Iran. Tel: +982182883578; Email: Mohammad.gholami@modares.ac.ir
}

Received 2020 August 09; Revised 2020 August 17; Accepted 2020 September 16.

\begin{abstract}
Background: There have been a limited number of studies on the relationships between time and occupational and demographical variables with the mean changes of low-frequency hearing (LFH) and high-frequency hearing $(\mathrm{HFH})$.

Objectives: This study investigated the rate of occupational noise-induced hearing loss (NIHL) due to working in the steel industry and associated effective factors.

Methods: This historical cohort study was conducted within 2000 to 2010. Two LFH and HFH definitions of NIHL were used in this study. The average changes of LFH and HFL were considered the response variables. In addition, time and occupational (i.e., shift work and work experience) and demographic (i.e., age and educational level) variables were regarded as the independent variables. For data analysis, Bayesian multivariate multilevel modeling using skew distribution and OpenBUGS (version 3.2.2) and R (version 2.13.2) software were used in this study.

Results: The present study was performed on 1,959 male workers with a mean age of $36.64 \pm 3.92$ years. Among these subjects, 913 (46.6\%), 134 (6.8\%), and 912 (46.6\%) participants were day workers, weekly-rotating shift workers, and routinely-rotating shift workers, respectively. The obtained results showed that age, work experience, educational level, and shift work had significant relationships with the changes of LFH and $\mathrm{HFH}$.

Conclusion: Overall, the findings of this 10-year historical cohort study demonstrated a relationship between time and demographic and occupational variables with the changes of LFH and HFL. Therefore, it is recommended to design preventive measures to reduce the deleterious effects of such variables on LFH and HFL.

Keywords: Hearing problem, Iran, Occupational, Multilevel modeling, Steel worker
\end{abstract}

\section{Background}

Noise-induced hearing loss (NIHL) remains one of the most prevalent occupational disorders, arising across a wide variety of industries (1). This problem is a well-known health problem related to otolaryngology (2). The major cause of NIHL is noise pollution in the workplace (3-5). Noise exposure (6, 7) may have adverse effects on the functioning of different parts of the body, such as heart (8) and blood circulatory system (9), and individuals' performance (10). The risk of occupational NIHL varies from one workplace to another. Steelmaking is one of the high-risk occupations in the area of hearing problems $(11,12)$. The NIHL can be avoided by means of a control hierarchy prioritizing the use of engineering controls over administrative controls and personal protective equipment (13).

Since hearing loss is completely preventable (14) and due to uninterrupted occupational noise exposure, it is necessary to determine the long-term effects of uninterrupted hearing noise exposure. The two most common types of hearing loss are known as low-frequency hearing (LFH) and high-frequency hearing (HFH). The diagnosis of $\mathrm{LFH}$ and $\mathrm{HFH}$ is established after a hearing test. If an individual has LFH, the audiogram will show a slope to the right indicating trouble hearing frequencies within 1 to 2 $\mathrm{kHz}$; however, for $\mathrm{HFH}$ the range is within 2 to $8 \mathrm{kHz}$.

The cut-off point for the determination of NIHL is different in several studies; therefore, LFH and HFH in this study were considered the continuous variables. On the other hand, because LFH and HFH are correlated with each other, multivariate analyses (15) are suitable candidates for such data. In addition, data collection for a cohort study tends to longitudinal data, and the best choice for longitudinal data is multilevel analysis (16). Another problem in the analysis of this field is data asymmetry. One of the best techniques for the analysis of asymmetric data is the use of skew distribution (17).

\section{Objectives}

Actually, in this study, three statistical methods (i.e., multivariate analysis, multilevel analysis, and skew distribution) were combined and used for analyzing the rate of occupational NIHL due to working in the steel industry and associated effective factors. 


\section{Methods}

This historical cohort study was carried out on 1,959 employees in Isfahan, Iran, who were subjected to audiometric tests within 2000 to 2010 . The inclusion criteria were male gender, official employment, $25 \leq$ age $\leq 50$ years, $3 \leq$ work experience $\leq 25$ years, and no hearing problem at the first examination. In addition, the exclusion criteria were retirement, death, or withdrawal from the study without any missing value in medical records (Figure 1). Those participants who had noise safety evaluation during the study period and met the inclusion criteria also joined the present study. In the current study, an ALPS diagnostic audiometer (Model AD 229e, Interacoustics, Denmark) was used by a trained audiologist to calculate hearing thresholds at different frequencies of air conduction (AC).

The test was conducted in an enclosed acoustic room following the requirements of the American National Standards Institute S3.1-1991, away from the workplace with at least $16 \mathrm{~h}$ of interval from the last exposure. In this study, pure-tone hearing thresholds for AC is measured in both ears at $1,1.5,2$, 4,6 , and $8 \mathrm{kHz}$. In addition, two separate NIHL definitions were established as the average binaural pure-tone average. In this study, HFH and LFH were defined as $4 \mathrm{kHz}+6 \mathrm{kHz}+8 \mathrm{kHz} / 3$ and $1 \mathrm{kHz}+1.5$ $\mathrm{kHz}+2 \mathrm{kHz} / 3$, respectively. The changes of HFH and LFH from the baseline were considered the response variables. In addition, age, work experience, educational level, and shift work were regarded as the independent variables.

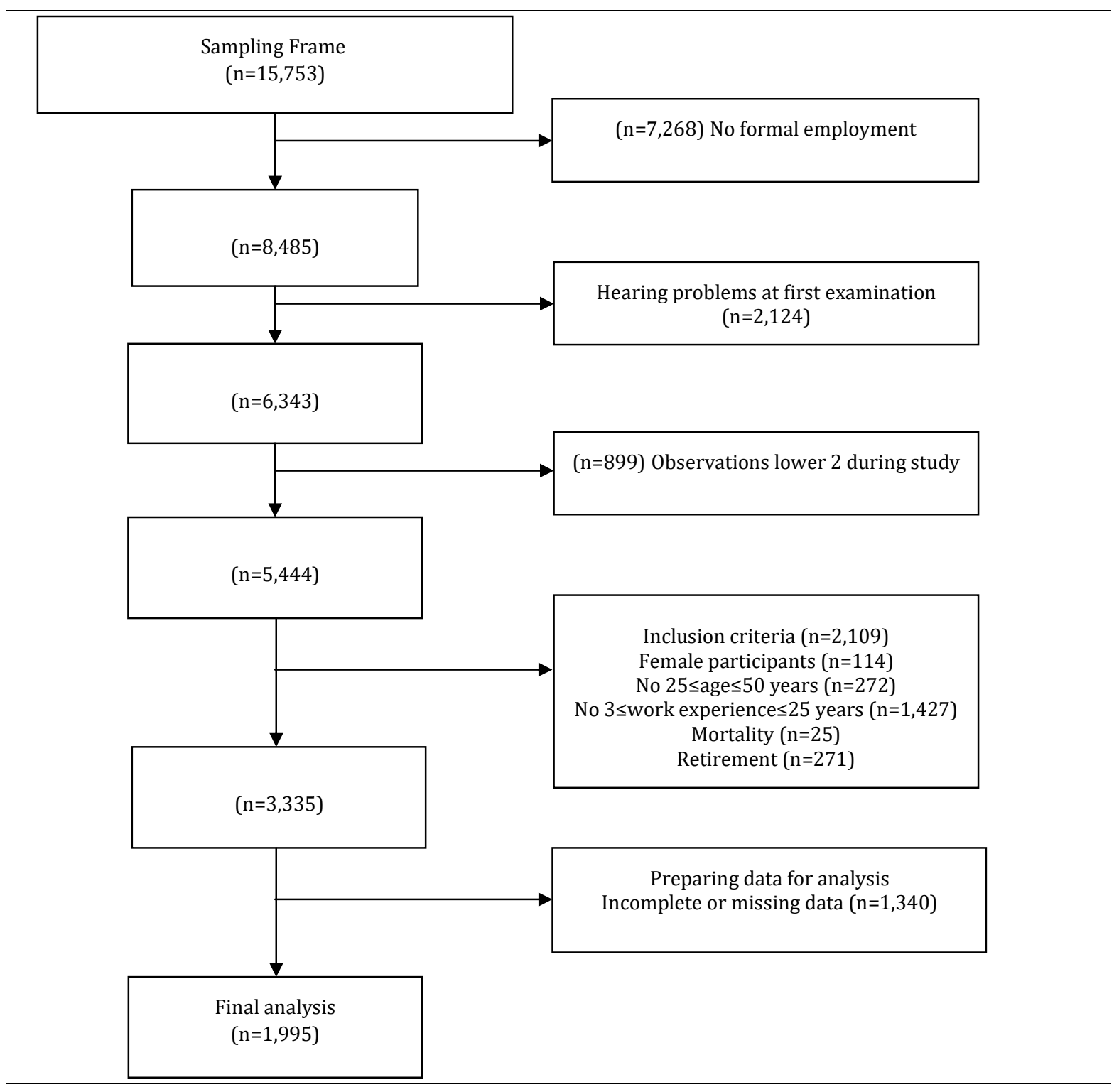

Figure 1. Cohort flow diagram 
The schedule of shift time (i.e., routinely-rotating shift workers, weekly-rotating shift workers, and day workers) by Gholami Fesharaki et al. was used in this study (18). The Ethics Committee of Faculty of Medical Sciences of Tarbiat Modares University, Tehran, Iran, approved the present study (code no.: IR.MODARES.REC.1397.223).

\subsection{Statistical Analysis}

The statistical analysis was performed using OpenBUGS (version 3.2.2) and $\mathrm{R}$ (version 2.13.2) software. The association between the effective factors and changes of LFH and HFH from the baseline was investigated by the Bayesian multivariate multilevel modeling using skew distribution. In this model, the distribution for the changes of LFH and HFH from the baseline was considered the multivariate skew t-distribution. The model was defined as follows:

$$
\left[\begin{array}{l}
\mathrm{DLFH}_{\mathrm{i}} \\
\mathrm{DHFH}_{\mathrm{i}}
\end{array}\right] \sim \mathrm{Mt}\left(\left[\begin{array}{l}
\mu_{1 \mathrm{i}} \\
\mu_{2 \mathrm{i}}
\end{array}\right], \Sigma, \mathrm{df}\right)
$$

where $\mathrm{Mt}$ is a multivariate $\mathrm{t}$-distribution with the location of $\left[\begin{array}{l}\mu_{\mu_{i}} \\ \mu_{2 i}\end{array}\right]$ scale parameter of $\Sigma$, and degree of freedom of di. In this formula, $\mu_{1 \mathrm{i}}$ is defined as follows:

$$
\beta_{01}+\beta_{11} x_{1 i}+\beta_{21} x_{2 i}+\cdots+\beta_{k 1} x_{7 i}+u_{1 i}+v_{1 i}+\lambda_{1}\left|z_{1 i}\right|
$$

In addition, $\mu_{2 \mathrm{i}}$ is defined as follows:

$$
\beta_{02}+\beta_{12} x_{1 i}+\beta_{22} x_{2 i}+\cdots+\beta_{27} x_{k i}+u_{2 i}+\gamma_{2 i}+\lambda_{2}\left|z_{2 i}\right|
$$

where $x_{k}$ are the explanatory variables; $7_{1 i}$ in addition $\mathcal{L}_{\mathrm{ai}}$ are the two random variables with tdistribution (location=0; scale $=1$ ); moreover, $u_{1 i}$ and $u_{2 i}$ are the two random variables with a normal distribution; $N\left(0, \sigma_{u 1}^{2}\right)$ and $N\left(0, \sigma_{u 2}^{2}\right)$ are considered for the dependency related to the left and right ear for LFH and HFH, respectively; in addition, $v_{1 i}$ and $\nu_{2 i}$ are the two random variables with a normal distribution; $N\left(0, \sigma_{v 1}^{2}\right)$ and $N\left(0, \sigma_{v 2}^{2}\right)$ are regarded for the dependency related to the repetition for $\mathrm{LFH}$ and $\mathrm{HFH}$, respectively; furthermore, $\lambda_{1}$ and $\lambda_{2}$ are the parameters of skewness in the response variables for LFH and HFH, respectively.

In this study, the prior distribution for all the betas and skewness parameters was considered a normal distribution $N(0,100)(N(0,100))$. Moreover, for variance parameters $\left(\sigma_{v 1}^{2}, \sigma_{v 2}^{2}, \sigma_{u 1}^{2}, \sigma_{u 2}^{2}\right)$ the gamma distribution $(\alpha=\beta=0.001)$, for $\Sigma$ parameters the wisahrt $\left(\left[\begin{array}{cc}0.001 & 0 \\ 0 & 0.001\end{array}\right], 2\right)$ distribution, and for degree of freedom (df) t-distribution and Chi-square distribution $\left(\chi^{2}(5)\right)$ were considered, respectively.

In the present study, the obtained results were based on 100 draws from a Markov Chain Monte Carlo of length 11,000 iterations with a burn-in of 1000 iterations in order to characterize posterior distributions for the beta parameters. The p-values of less than 0.05 were considered statistically significant.

\section{Results}

The present study was carried out on a total of 1,959 male workers with a mean age of $36.64 \pm 3.92$ years and mean work experience of $11.70 \pm 3.06$. Among these participants, 913 (46.6\%), 134 (6.8\%), and 912 (46.6\%) individuals were day workers, weekly-rotating shift workers, and routinely-rotating shift workers, respectively. Table 1 tabulates the demographic information of the study participants. Most of the study participants were reported with

\begin{tabular}{|c|c|c|c|c|c|c|c|}
\hline \multirow{2}{*}{ Variable } & \multirow{2}{*}{ Level } & \multicolumn{2}{|c|}{ Frequency } & \multicolumn{2}{|c|}{ LFH } & \multicolumn{2}{|c|}{ HFH } \\
\hline & & $\mathbf{n}$ & $\%$ & Mean & SD & Mean & SD \\
\hline \multirow{5}{*}{ Age (year) } & $\leq 30$ & 81 & 4.1 & 4.16 & 13.37 & 3.85 & 7.14 \\
\hline & $30-35$ & 610 & 31.1 & 5.06 & 12.19 & 2.58 & 4.73 \\
\hline & $36-40$ & 902 & 46.0 & 4.88 & 13.58 & 2.49 & 5.45 \\
\hline & $41-45$ & 313 & 16.0 & 4.89 & 14.05 & 2.59 & 5.73 \\
\hline & $\geq 46$ & 53 & 2.7 & 4.44 & 14.97 & 3.00 & 6.60 \\
\hline \multirow{4}{*}{$\begin{array}{l}\text { Work } \\
\text { experience } \\
\text { (year) }\end{array}$} & $\leq 5$ & 137 & 7.0 & 4.50 & 14.04 & 3.68 & 7.58 \\
\hline & $6-10$ & 221 & 11.3 & 5.19 & 12.81 & 2.70 & 5.04 \\
\hline & $11-15$ & 1428 & 72.9 & 4.97 & 13.08 & 2.48 & 5.10 \\
\hline & $\geq 16$ & 173 & 8.8 & 4.57 & 14.58 & 2.18 & 6.32 \\
\hline \multirow{2}{*}{$\begin{array}{l}\text { Educational } \\
\text { level }\end{array}$} & Nonacademic & 1470 & 75.0 & 5.00 & 13.18 & 2.73 & 5.35 \\
\hline & Academic & 489 & 25.0 & 4.82 & 13.47 & 2.50 & 5.44 \\
\hline \multirow{3}{*}{ Shift schedule } & Day workers & 913 & 46.6 & 4.73 & 13.30 & 2.68 & 5.44 \\
\hline & Routinely-rotating shift workers & 912 & 46.6 & 5.21 & 13.13 & 2.75 & 5.29 \\
\hline & Weekly-rotating shift workers & 134 & 6.8 & 4.61 & 13.79 & 2.09 & 5.46 \\
\hline
\end{tabular}

Table 1. Demographic information of participants in addition to mean and standard deviation of low-frequency hearing and highfrequency hearing at first examination

LFH: Low-frequency hearing

HFH: High-frequency hearing

SD: Standard deviation 
Table 2. Relationship between study variables regarding changes of low-frequency hearing and high-frequency hearing from baseline using Bayesian multivariate multilevel modeling and skew distribution

\begin{tabular}{|c|c|c|c|c|c|c|c|c|}
\hline \multirow{3}{*}{$\begin{array}{l}\text { Independent variable } \\
\text { Intercept }\left(\beta_{0}\right)\end{array}$} & \multicolumn{4}{|c|}{$l . F H_{t}-l . F H_{0}$} & \multicolumn{4}{|c|}{$\mathrm{HFl}_{\mathrm{t}}-\mathrm{HFl}_{\mathrm{o}}$} \\
\hline & \multirow{2}{*}{$\begin{array}{c}\text { Estimate } \\
-1.617\end{array}$} & \multirow{2}{*}{$\begin{array}{c}\begin{array}{c}\text { Standard } \\
\text { error }\end{array} \\
0.102\end{array}$} & \multicolumn{2}{|c|}{$\begin{array}{c}95 \% \\
\text { Credible interval }\end{array}$} & \multirow{2}{*}{$\begin{array}{c}\text { Estimate } \\
-5.758\end{array}$} & \multirow{2}{*}{$\begin{array}{c}\begin{array}{c}\text { Standard } \\
\text { error }\end{array} \\
0.291\end{array}$} & \multicolumn{2}{|c|}{$\begin{array}{c}95 \% \\
\text { Credible interval }\end{array}$} \\
\hline & & & -1.827 & -1.426 & & & -6.208 & -5.276 \\
\hline Age $\left(\beta_{1}\right)$ & -0.032 & 0.002 & -0.037 & -0.029 & 0.185 & 0.006 & 0.174 & 0.193 \\
\hline Work experience $\left(\beta_{2}\right)$ & 0.218 & 0.012 & 0.195 & 0.236 & 0.018 & 0.008 & 0.004 & 0.034 \\
\hline Education level $\left(\beta_{\mathfrak{g}}\right)$ & 0.073 & 0.022 & 0.044 & 0.114 & 0.059 & 0.010 & 0.038 & 0.077 \\
\hline Time (year) $\left(\beta_{4}\right)$ & 0.408 & 0.012 & 0.384 & 0.432 & 0.576 & 0.012 & 0.552 & 0.6 \\
\hline RRS workers $\left(\beta_{\mathrm{g}}\right)$ & -1.219 & 0.105 & -1.443 & -1.059 & -0.341 & 0.198 & -0.726 & 0.062 \\
\hline WRS workers $\left(\beta_{6}\right)$ & -0.734 & 0.089 & -0.923 & -0.574 & 0.695 & 0.362 & -0.015 & 1.405 \\
\hline Day worker $\left(\beta_{7}\right)$ & \multicolumn{4}{|c|}{ Considered reference category } & \multicolumn{4}{|c|}{ Considered reference category } \\
\hline$\sigma_{U}^{2}$ & 0.018 & 0.004 & 0.012 & 0.016 & 10.424 & 0.452 & 9.498 & 10.140 \\
\hline$\sigma_{v}^{2}$ & 8.080 & 0.280 & 7.551 & 7.883 & 21.754 & 1.040 & 20.044 & 21.020 \\
\hline$\sigma_{g}^{2}$ & 2.463 & 0.049 & 2.352 & 2.552 & 11.767 & 0.227 & 11.265 & 11.620 \\
\hline$\lambda$ & -0.024 & 0.026 & -0.072 & -0.043 & -0.556 & 0.061 & -0.675 & -0.595 \\
\hline$\rho$ & 0.270 & 0.008 & 0.255 & 0.265 & 0.270 & 0.008 & 0.255 & 0.265 \\
\hline dif & 2.607 & 0.051 & 2.472 & 2.588 & 2.607 & 0.051 & 2.472 & 2.588 \\
\hline
\end{tabular}

$\lambda$ : Skewness parameter, $\rho$ : Correlation of low-frequency hearing and high-frequency hearing, $d f$ : Degree of freedom, $\sigma_{g}^{2}$ : Error variance, $\sigma_{v}^{2}$ : Repetition variance, $\sigma_{u}^{2}$ : Between-ear variance, $R$ RS: Routinely-rotating shift, WRS: Weekly-rotating shift

nonacademic education. Furthermore, most of the study subjects were reported within the age range and with a work experience of 36-40 and 11-15 years, respectively.

Table 2 shows the relationship between the study variables regarding the changes of LFH and HFH from the baseline by Bayesian multivariate multilevel modeling using skew distribution. The obtained results of the current study demonstrated that the age, work experience, educational level, and shift work had significant relationships with the changes of LFH and HFH. The significance of the parameters, such as $\sigma_{u}^{2}, \sigma_{v}^{2}, \sigma_{v}^{2}, \lambda, \rho$, and $d f$ demonstrated that the Bayesian multivariate multilevel modeling using skew distribution was a convenient model for analyzing the changes of LFH and HFH data.

Using the test statistics, it can be said that the time had the greatest effect on the changes of LFH and $\mathrm{HFH}$ among other variables. After the adjustment of the age and work experience, the results showed that LFH and HFH increased 0.408 and 0.576 per year, respectively. The findings of the present study showed the significant relationship between shift work and LFH changes. Shift workers have a lower average of LFH changes in comparison to the day workers. This difference in the routinely-rotating shift workers was higher than that reported for the weekly-rotating shift workers.

\section{Discussion}

The most common occupational health condition following musculoskeletal problems and respiratory diseases (due to long-term workplace noise exposure) is NIHL (19). Although countermeasures in many workplaces have effectively lowered noise levels, noise remains a significant occupational risk factor, and NIHL is one of the major occupational diseases worldwide (19-21). The result of the present study showed a significant relationship between shift work and LFH changes. The shift workers had a lower average of LFH changes in comparison to that of the day workers. A lack of the use of protective equipment among the day workers, compared to that reported for the shift workers $(15,16)$, can be a reason for such a relationship.

The results of this study are consistent with the findings of studies performed by Wang et al. (22), Chou et al. (23), Holzmüller (24), and Golmohammadi et al. (25) and inconsistent with the findings of a study conducted by Zare et al. (26). There was no strong evidence that work patterns, including shift work or overtime, affected safety. Protective compensatory strategies or experience may maintain safe working practices (27). Wang et al. showed that the association between short duration of shift work and bilateral hearing loss was not significant in men when those with occupational noise exposure were excluded (22).

Chou et al. (23) demonstrated that the severity of hearing loss in both ears was significantly lower in subjects who worked in a 12-hour shift. In conclusion, working in a 12-hour shift followed by a day off is the best condition for workers, and hearing 
protection should be provided in high-noise areas. The result of the current study similar to those reported for previous studies showed the relationship between age $(25,28,29)$ and work experience (30) with LFH and HFL changes. The strengths of the present study were the use of an effective type of study (i.e., historical cohort study), appropriate sample size, and homogeneity of the study population. Some of the limitations of the study were no evaluation of the NIHL family and disability history to determine previous job interactions, sleep, income, and stress as potential confounding factors.

\section{Conclusion}

Overall, the findings of a 10-year historical cohort study demonstrated a relationship between shift work and change of LFH. Therefore, it is recommended to design preventive measures for the reduction of the deleterious effects of shift work on LFH.

\section{Acknowledgements}

The authors would like to gratefully acknowledge the financial support of Tarbiat Modares University and express their gratitude to all the staff, particularly the personnel of the Industrial Medicine Department of Esfahan Mobarakeh Steel Company for their cooperation throughout the project.

\section{Footnotes}

Authors' Contribution: Abolfazl Nikpour managed and analyzed the data in addition to writing the manuscript. Mohammad Gholami Fesharaki supervised the study, wrote the statistical code, and revised the manuscript.

Conflicts of interest: The authors declare that there is no conflict of interest.

Ethical Approval: This cohort study was approved by the Ethics Committee of School of Medicine at Tarbiat Modares University (code no.: IR.MODA RES.REC.1397.223) and conducted in accordance with the ethical standards laid down in the 1964 Declaration of Helsinki and its later amendments.

Funding/Support: This study was funded by Tarbiat Modares University and extracted from a PhD dissertation (grant no.: 1397.223).

\section{References}

1. Mirza R, Kirchner DB, Dobie RA, Crawford J. occupational noise-induced hearing loss. Occupational Environ Med. 2018;60(9):e498-501. doi: 10.1097/JOM.0000000000001423. [PubMed: 30095587].

2. Solanki JD, Mehta HB, Shah CJ, Gokhale PA. A study of effect of shift work, sex, and smoking on development of onihl in plastic weavers. Indian J Otol. 2013;19(1):1. doi: 10.4103/09717749.108148.

3. Chou YF, Lai JS, Kuo HW. Effects of shift work on noise-induced hearing loss. Noise Health. 2009;11(45):185-8. doi: 10.4103/
1463-1741.56210.

4. Kim JS. Prevalence and factors associated with hearing loss and hearing aid use in korean elders. Iran J Public Health 2015;44(3):308-17. [PubMed: 25905073].

5. Amjad-Sardrudi H, Dormohammadi A, Golmohammadi R, Poorolajal J. Effect of noise exposure on occupational injuries: a cross-sectional study. J Res Health Sci. 2012;12(2):101-4. [PubMed: 23241520].

6. Eggermont JJ. Effects of long-term non-traumatic noise exposure on the adult central auditory system. hearing problems without hearing loss. Hear Res. 2017;352:12-22. doi: 10.1016/j.heares.2016.10.015. [PubMed: 27793584].

7. Jiang W, Zhao F, Guderley N, Manchaiah V. Daily music exposure dose and hearing problems using personal listening devices in adolescents and young adults: a systematic review. Int J Audiol. 2016;55(4):197-205. doi: 10.3109/14992027. 2015.1122237. [PubMed: 26768911].

8. Kempen EV, Casas M, Pershagen G, Foraster M. WHO environmental noise guidelines for the european region: a systematic review on environmental noise and cardiovascular and metabolic effects: a summary. Int $J$ Environ Res Public Health. 2018;15(2):379. doi: 10.3390/ijerph15020379. [PubMed: 29470452].

9. Neghab M, Maddahi M, Rajaeefard A. Hearing impairment and hypertension associated with long term occupational exposure to noise. Iran Red Crescent Med J. 2009;11(2):160-5.

10. Halvani GH, Zare M, Barkhourdari A. Noise induced hearing loss among textile workers of Taban factories in Yazd. J Birjand Univ Med Sci. 2009;15(4):69-74.

11. Nyarubeli IP, Tungu AM, Moen BE, Bratveit M. Prevalence of noise-induced hearing loss among Tanzanian iron and steel workers: a cross-sectional study. Int J Environ Res Public Health. 2019;16(8):1367. doi: 10.3390/ijerph16081367. [PubMed: 30995750].

12. Singh LP, Bhardwaj A, Kumar DK. Prevalence of permanent hearing threshold shift among workers of indian iron and steel small and medium enterprises: a study. Noise Health. 2012;14(58):119-28. doi: 10.4103/1463-1741.97256. [PubMed: 22718110].

13. Phillips A, Cooney R, Harris Z, Myrtil D, Hodgson M. Noise and occupational medicine: common practice problems. J Occup Environ Med. 2019;61(12):1019-29. doi: 10.1097/JOM.0000 000000001728. [PubMed: 31592942].

14. Rogha M, Amiridavan M, Abtahi SH, Sonbolestan SM, Abtahi SM. Early detection of noise induced hearing loss by extended high frequency audiometery. J Isfahan Med Sch. 2007; 25(85):16-22.

15. Rencher AC. Methods of multivariate analysis. $2^{\text {nd }}$ ed. New Jersey: John Wiley \& Sons; 2003.

16. Gholami-Fesharaki M, Kazemnejad A, Zayeri F, Sanati J, Akbari H. A retrospective cohort study on factors associated blood pressure using multilevel modeling. ARYA Atheroscler. 2013, 9(5):293-9. [PubMed: 24302938].

17. Gholami-Fesharaki M, Kazemnejad A, Zayeri F, Sanati J, Akbari $\mathrm{H}$. Historical cohort study on the factors affecting blood pressure in workers of polyacryl iran corporation using bayesian multilevel modeling with skew t distribution. Iran Red Crescent Med J. 2013;15(5):418-23. doi: 10.5812/ ircmj.10930. [PubMed: 24349731].

18. Gholami Fesharaki M, Kazemnejad A, Zayeri F, Rowzati M, Akbari H. Historical cohort study of shift work and blood pressure. Occup Med (Lond). 2014;64(2):109-12. doi: 10.1093/ occmed/kqt156. [PubMed: 24526704].

19. Rubak T, Kock SA, Koefoed-Nielsen B, Bonde JP, Kolstad HA. The risk of noise-induced hearing loss in the danish workforce. Noise Health. 2006;8(31):80-7. doi: 10.4103/1463-1741.33538. [PubMed: 17687183].

20. Voaklander DC, Franklin RC, Challinor K, Depczynski J, Fragar LJ. Hearing screening program impact on noise reduction strategies. J Agric Saf Health. 2009;15(2):119-27. doi: 10.13031/2013.26799. [PubMed: 19496341].

21. Lusk SL. Preventing noise-induced hearing loss. Nurs Clin North Am. 2002;37(2):257-62. doi: 10.1016/s0029-6465(01) 00005-6. [PubMed: 12389266]. 
22. Wang D, Zhou Y, Ma J, Xiao L, Cao L, Zhou M, et al. Association between shift work and hearing loss: the Dongfeng-Tongji cohort study. Hear Res. 2019;384:107827. doi: 10.1016/j. heares.2019.107827. [PubMed: 31683075].

23. Chou YF, Lai JS, Kuo HW. Effects of shift work on noise-induced hearing loss. Noise Health. 2009;11(45):185-8. doi: 10.4103/1463-1741.56210.

24. Holzmüller M, Seibt A, Jakubowski A, Friedrichsen G. Studies on the combined effects of shift work and noise on permanent hearing loss. Z Gesamte Hyg. 1990;36(9):501-2. [PubMed: 2238742].

25. Golmohammadi R, Darvishi E. The combined effects of occupational exposure to noise and other risk factors - a systematic review. Noise Health. 2019;21(101):125-41. doi: 10.4103/nah.NAH_4_18. [PubMed: 32719300].

26. Zare S, Nassiri P, Monazzam MR, Pourbakht A, Azam K, Golmohammadi T. Evaluation of distortion product otoacoustic emissions (dpoaes) among workers at an industrial company exposed to different industrial noise levels in 2014. Electron
Physician. 2015;7(3):1126-34. doi: 10.14661/2015.1126-1134. [PubMed: 26388979].

27. Farrow A, Reynolds F. Health and safety of the older worker. Occup Med (Lond). 2012;62(1):4-11. doi: 10.1093/occmed/ kqr148. [PubMed: 22201131].

28. Li JH, Tao ZM, Ruan YM, Huang LL, Duan CW, Wang Z. Analysis of factors affecting the noise-induced high frequency hearing loss of male workers in a vehicle manufacturing enterprise. Zhonghua Lao Dong Wei Sheng Zhi Ye Bing Za Zhi. 2019;37(10):760-4. doi: 10.3760/cma.j.issn.1001-9391.2019. 10.009. [PubMed: 31726507 ]

29. Irion H. Effect of noise and other factors damaging to hearing on hearing loss. Laryngol Rhinol Otol (Stuttg). 1984;63(2):71-8. [PubMed: 6700339].

30. Corrêa Filho HR, Costa LS, Hoehne EL, Pérez MA, Nascimento LC, de Moura EC. Noise-induced hearing loss and high blood pressure among city bus drivers. Rev Saude Publica. 2002; 36(6):693-701. doi: 10.1590/s0034-89102002000700006. [PubMed: 12488935]. 